\title{
Article \\ A Novel Heat Shock Transcription Factor (ZmHsf08) Negatively Regulates Salt and Drought Stress Responses in Maize
}

\author{
Jing Wang, Li Chen, Yun Long, Weina Si $\mathbb{D}^{+}$, Beijiu Cheng * and Haiyang Jiang * \\ National Engineering Laboratory of Crop Stress Resistance Breeding, School of Life Sciences, \\ Anhui Agricultural University, Hefei 230036, China; wangjing@stu.ahau.edu.cn (J.W.); \\ c10226@stu.ahau.edu.cn (L.C.); $20720531 @$ stu.ahau.edu.cn (Y.L.); weinasi@ahau.edu.cn (W.S.) \\ * Correspondence: chengbeijiu2007@163.com (B.C.); hyjiang@ahau.edu.cn (H.J.)
}

check for updates

Citation: Wang, J.; Chen, L.; Long, Y.; Si, W.; Cheng, B.; Jiang, H. A Novel Heat Shock Transcription Factor (ZmHsf08) Negatively Regulates Salt and Drought Stress Responses in Maize. Int. J. Mol. Sci. 2021, 22, 11922. https://doi.org/10.3390/ ijms222111922

Academic Editor: Endang M. Septiningsih

Received: 19 September 2021

Accepted: 29 October 2021

Published: 3 November 2021

Publisher's Note: MDPI stays neutral with regard to jurisdictional claims in published maps and institutional affiliations.

Copyright: (c) 2021 by the authors. Licensee MDPI, Basel, Switzerland. This article is an open access article distributed under the terms and conditions of the Creative Commons Attribution (CC BY) license (https:// creativecommons.org/licenses/by/ $4.0 /)$.
Abstract: Heat shock transcription factors (HSFs) play important roles in plant growth, development, and stress responses. However, the function of these transcription factors in abiotic stress responses in maize (Zea mays) remains largely unknown. In this study, we characterized a novel HSF transcription

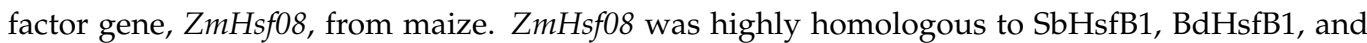
OsHsfB1, and has no transcriptional activation activity. The expression profiles demonstrated that $\mathrm{ZmHsf08}$ was differentially expressed in various organs of maize and was induced by salt, drought, and abscisic acid (ABA) treatment. Moreover, the overexpression of $\mathrm{ZmHsf08}$ in maize resulted in enhanced sensitivity to salt and drought stresses, displaying lower survival rates, higher reactive oxygen species (ROS) levels, and increased malondialdehyde (MDA) contents compared with wild-

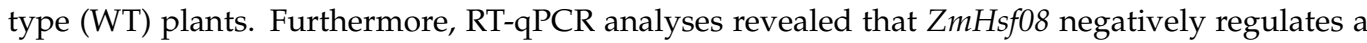
number of stress/ABA-responsive genes under salt and drought stress conditions. Collectively, these results indicate that $\mathrm{ZmHsf08}$ plays a negative role in response to salt and drought stresses in maize.

Keywords: maize; $\mathrm{ZmHsf08;} \mathrm{transcription} \mathrm{factor;} \mathrm{salt} \mathrm{stress;} \mathrm{drought} \mathrm{stress}$

\section{Introduction}

Plants are prone to encountering environmental stresses during all aspects of plant growth and development, resulting in devastating damage to the survival and production of the plants. Among these environmental factors, drought and salt stress are the most important challenges limiting crop growth and grain yield [1,2]. On the one hand, salt and drought stress cause dehydration, which in its turn results in ionic and osmotic stress, destroying cellular homeostasis; on the other hand, salt and drought stress trigger oxidative stress, which produces reactive oxygen species (ROS) and provokes damages to membrane lipids, proteins, and DNA, resulting in plant wilting and even plant death $[3,4]$.

Plants have developed sophisticated tolerance mechanisms to survive drought and salt stress. Many key factors are involved in drought and salt stress responses, including kinases [5,6], ion transporters [7,8], ROS [3,9], abscisic acid (ABA) [10,11], and transcription factors (TFs) [12,13]. A wealth of studies has demonstrated that many TF families, such as dehydration-responsive element-binding protein (DREB), WRKY, v-myb avian myeloblastosis viral oncogene homolog (MYB), basic leucine zipper (bZIP), and HSF, play a pivotal role in the transcriptional regulation of genes during abiotic stress responses [14-18]. TFs activate the transcription of stress-responsive genes by binding to their promoters, resulting in enhanced stress tolerance in plants [19]. HSFs are an important gene family of TFs, which are involved in plant growth, development, and stress response. Since the first plant HSF was isolated from tomato in the 1990s, a large number of plant HSFs have been identified and cloned [20]. For example, there are 21 HSFs in Arabidopsis that have been identified [21], 38 in soybean [22], 31 in maize [23], and 25 in rice [24]. Moreover, the maximum number of HSF families in plants was identified in wheat: at least 56 HSFs [25]. 
Generally, plant HSFs have conserved functional domains, including the N-terminal DNA binding domain (DBD), oligomerization domain (OD or HR-A/B), nuclear localization signal (NLS), and nuclear export signal (NES) [21,26]. In addition, plant HSFs are classified into three classes (HSFA, HSFB, and HSFC) based on the sequence characteristics of the OD domain. Interestingly, the HSFAs have short activator motifs (AHA motifs) located in their C-terminal domains, and they function as transcription activators, while class B and C HSFs lack the activation domain [18,21]. For the past few years, many studies reported the critical roles of HSFAs in plant response to various abiotic stresses. It has been determined in tomato and Arabidopsis that HsfA1s function as the master regulators in plant heat stress response (HSR) and are prerequisite for the activation of transcriptional networks [27-29]. The overexpression of $A t H s f A 1 b$ enhanced the water productivity of transgenic plants, resulting in increased resistance to drought [30]. HsfA2s, the direct target genes of HsfA1s, were reported as key regulators in plant HSR and other abiotic stress responses [18,31]. Overexpression of HsfA2 enhanced thermotolerance of transgenic plants [32-35]. Ectopic expression of rice OsHsfA2e in Arabidopsis enhanced thermotolerance and salt stress tolerance of transgenic plants [36]. Furthermore, HsfA3, HsfA6b, HsfA6f, and $H s f A 7 b$ also play an important role in abiotic stress tolerance in Arabidopsis, wheat, and rice [37-42].

In contrast to HSFAs, there was no evidence that HSFBs functioned as transcription activators on their own. In tomato, HsfB1 has been reported to act as a coactivator cooperating with HsfA1a or forming a functional triad with HsfA1a and HsfA2, regulating the expression of heat stress (HS)-responsive genes during plant HS responses [21,43,44]. Moreover, HsfB1 also cooperates with other transcriptional regulators to control target gene expression in abiotic stress responses. For example, ectopic expression of chickpea HSFB2 in Arabidopsis improved the drought tolerance of transgenic plants by increasing the expression of stress-responsive genes such as $R D 22, R D 26$, and $R D 29 A$ [45]. Decreased drought and salt tolerances were observed in rice plants over-expressing OsHsfB2b [46]. A study of HSF interaction showed that HsfB1 and HsfB2b have the capability to form complexes in vivo and might be involved in complex regulatory networks of signaling processes and stress responses [47].

Recently, 31 ZmHSFs were identified in maize and divided into 16 subclass A, 10 subclass $B$, and 5 subclass $C$ gene members [48]. Ectopic expression of maize $\mathrm{ZmHsf05}$ (members of subclass A2) in Arabidopsis improve the heat tolerance of transgenic plants [49,50]. Furthermore, overexpression of a member of subclass A1 (ZmHsfo6) in Arabidopsis enhances its salt stress tolerance [51]. However, the roles of ZmHSFs in plants' salt and drought tolerance are largely unknown. In this study, we cloned $\mathrm{ZmHsfO8}$, a member of subclass B1, and analyzed its function in salt and drought stress responses. We found that $\mathrm{ZmHsf08}$ was induced by $\mathrm{NaCl}$ and PEG treatments and localized to the nucleus. Notably, overexpression of $\mathrm{ZmHsf08}$ in maize significantly enhanced sensitivity to both salt and drought stresses. Our results suggest that $Z m H S F 08$ plays a negative role in regulation of salt and drought responses and serves as a gene resource for the improvement of maize against abiotic stresses in the future.

\section{Results}

\subsection{Gene Isolation and Sequence Analysis of $\mathrm{ZmHsf08}$}

The coding sequence of $\mathrm{ZmHsf08}$ was cloned from seedlings of the maize inbred B73. Sanger sequencing results showed that the coding sequence (CDS) of ZmHsfo8 was $897 \mathrm{bp}$ in length (Figure 1A). ZmHsf08 harbored 298 amino acids, including a conserved $\mathrm{N}$-terminal DNA binding domain (DBD), an oligomerization domain (OD), a nuclear export signal (NES), and a nuclear location signal (NLS) (Figure 1B). Further multiple sequence alignments and homologous analysis revealed that $\mathrm{ZmHsf08}$ exhibited high sequence similarity with other known HsfB1 proteins, homologous to the B1 subclass of ZmHsfs (Figure 1B,C). Most importantly, ZmHsf08 contained the core B3 repression domain 
(BRD, K/SV /KLFGVL/LTD), which is conserved in HsfB1 orthologs of five plant species (Figure 1B).

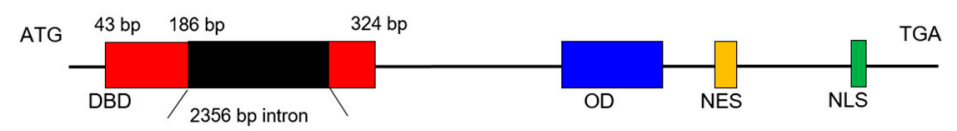

B

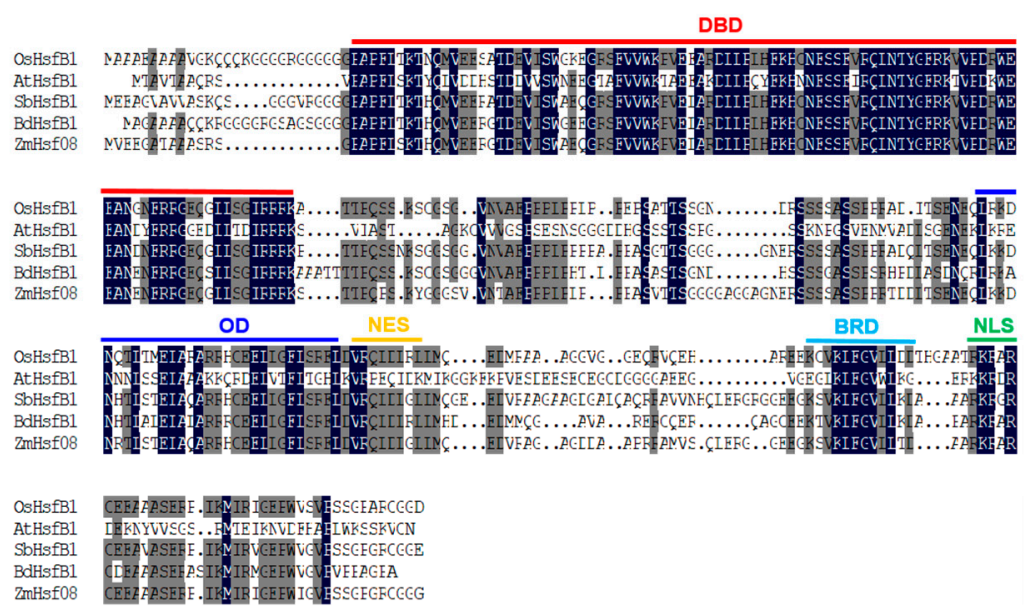

c

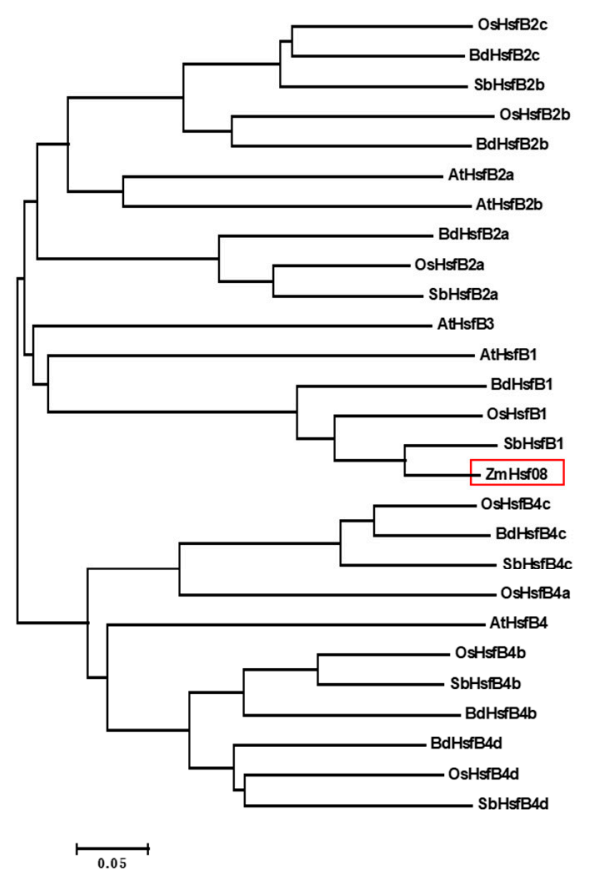

Figure 1. Identification of $\mathrm{ZmHsf08.} \mathrm{(A)} \mathrm{Schematic} \mathrm{representation} \mathrm{of} \mathrm{the} \mathrm{ZmHsf08}$ gene. A single 2356 bp intron existed in the

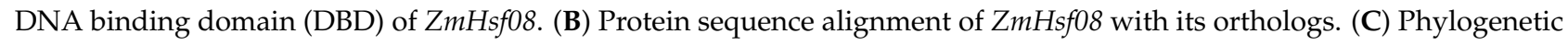
analysis of ZmHsf08 and other HsfBs proteins. The related protein names are as follows: AtHsfB1, NP_195416.1, Arabidopsis thaliana; OsHsfB1, XP_015611859.1, Oryza sativa; SbHsfB1, XP_002460330.1, Sorghum bicolor; and BdHsfB1, XP_003578229.1, Brachypodium distachyon.

\subsection{Subcellular Localization of $\mathrm{ZmHsf08}$}


proteins containing C-terminal and $\mathrm{N}$-terminal green fluorescent protein (GFP), respectively (Figure 2A). The recombinant protein was transiently expressed in maize protoplasts. The p1305-GFP and PMDC43, used as the control vectors, were expressed in the nucleus and cytoplasm. Both ZmHsf08-GFP and GFP-ZmHsf08 fluorescence signals were only concentrated in the nucleus, indicating that $\mathrm{ZmHsf08}$ was a nucleus-localized protein (Figure 2B).

\subsection{Tissue-Specific and Stress-Induced Expression Profiles of $\mathrm{ZmHsf08}$}

To investigate the tissue-specific expression of $\mathrm{ZmHsf08}$ in maize, we investigated the expression profiles of $\mathrm{ZmHsf08}$ in six tissues (roots, stem, leaves, corn-silk, tassels, and bract) by RT-qPCR (Figure 3A). The results indicated that the $\mathrm{ZmHsf08}$ constitutively expressed in all surveyed six tissues under the non-stress condition.

To explore the putative function of $\mathrm{ZmHsf08}$ in the responses to environmental stresses, we also assessed the expression profiles of $\mathrm{ZmHsf08}$ by RT-qPCR under different stress treatments, including $\mathrm{NaCl}, \mathrm{PEG}$, and exogenous ABA. As shown in Figure 3B, the expression level of $\mathrm{ZmHsf08}$ was downregulated to different degrees after exogenous ABA

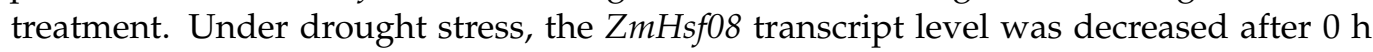
(Figure 3C). Similarly, ZmHsf08 expression was down-regulated following $\mathrm{NaCl}$ treatment (Figure 3D). These expression patterns indicated that $\mathrm{ZmHsf08}$ may function in response to abiotic stresses through the ABA-mediated pathway. 
A
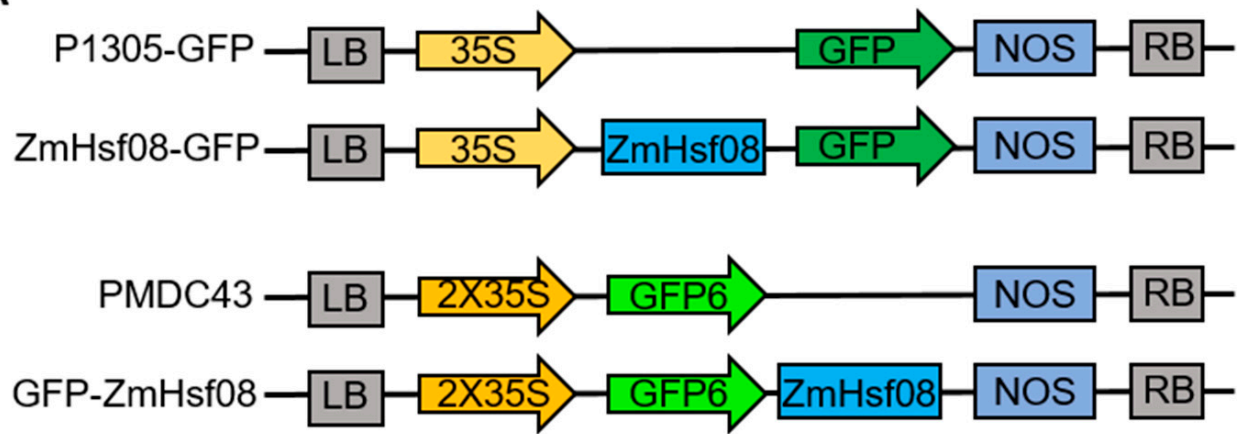

B

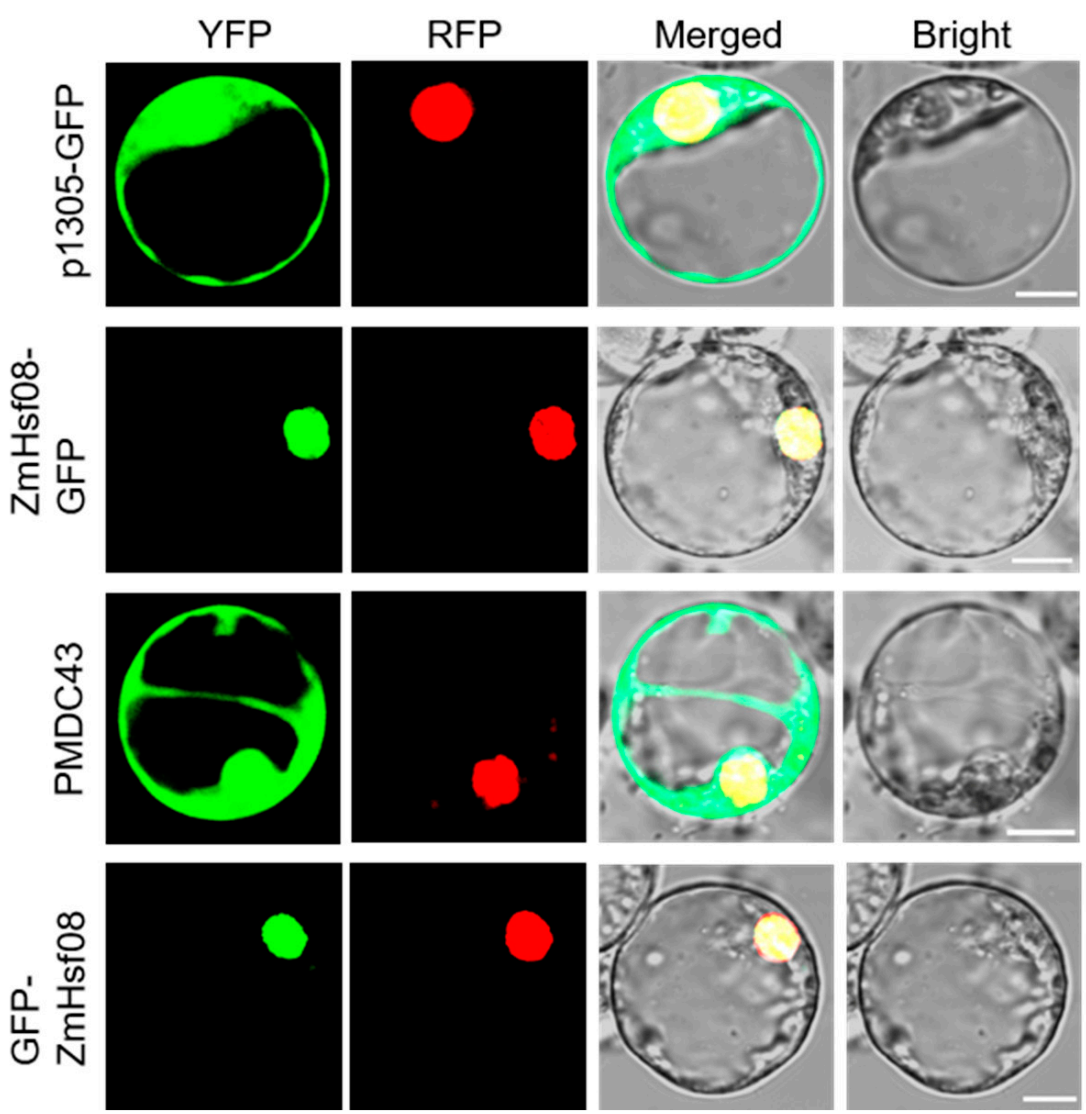

Figure 2. Subcellular localization of ZmHsf08. (A) Vector diagram of p1305-GFP, PMDC43, GFP$\mathrm{ZmHsf08}$ and $\mathrm{ZmHsf08-GFP.} \mathrm{(B)} \mathrm{Fusion} \mathrm{proteins} \mathrm{were} \mathrm{transiently} \mathrm{expressed} \mathrm{in} \mathrm{maize} \mathrm{protoplasts.}$ Control, p1305-GFP vector and PMDC43 vector; $\mathrm{ZmHsf08-GFP}$ and GFP-ZmHsf08, ZmHsf08 fused with GFP. RFP is a marker for nucleus localization. Bars $=10 \mu \mathrm{m}$.

\subsection{Overexpression of $\mathrm{ZmHsf08} \mathrm{Reduces} \mathrm{Salt} \mathrm{and} \mathrm{Drought} \mathrm{Tolerance} \mathrm{in} \mathrm{Maize}$}

It is suggested that $\mathrm{ZmHsf08}$ may play an important role in salt and drought stresses according to the expression pattern results. To investigate the function of $\mathrm{ZmHsf08}$ in maize, we generated $\mathrm{ZmHsf08-overexpressing} \mathrm{plants} \mathrm{(OE8-1} \mathrm{and} \mathrm{OE8-2).} \mathrm{The} \mathrm{transcript} \mathrm{level} \mathrm{of}$ $\mathrm{ZmHsf08}$ in the transgenic lines were examined by RT-qPCR. As shown in Figure 4B, significantly increased $\mathrm{ZmHsf08}$ expression levels were observed in OE8-1 and OE8-2 plants. 
A

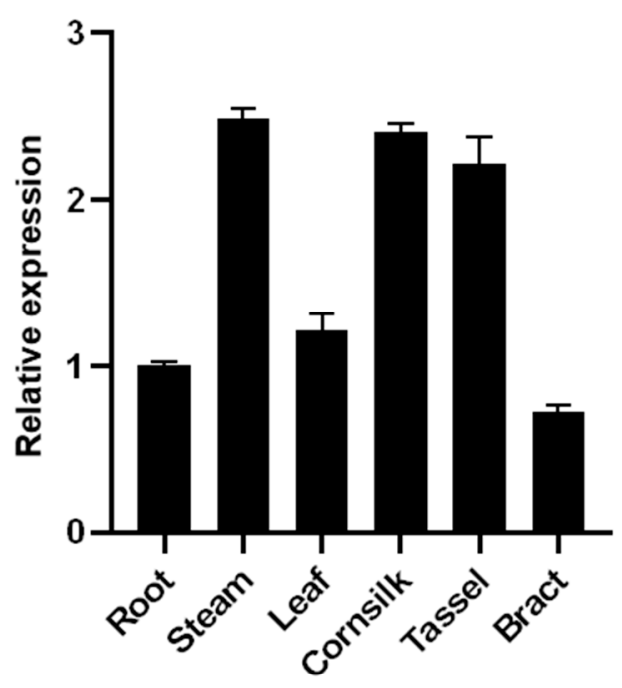

C

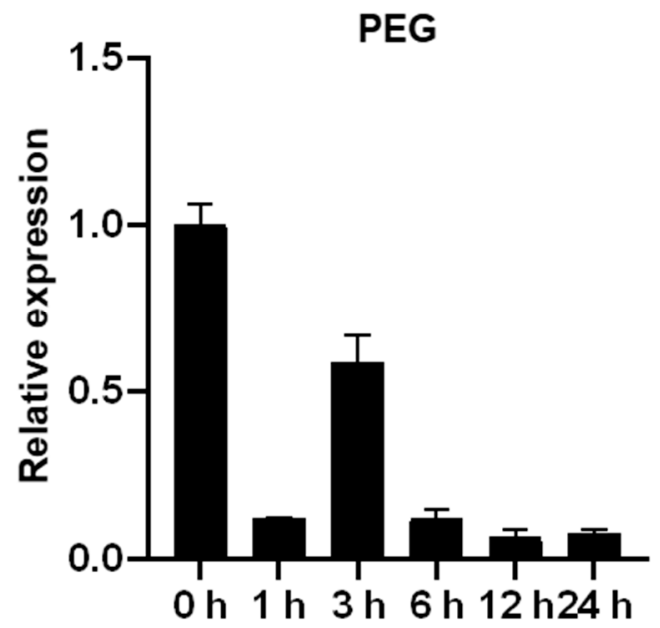

B
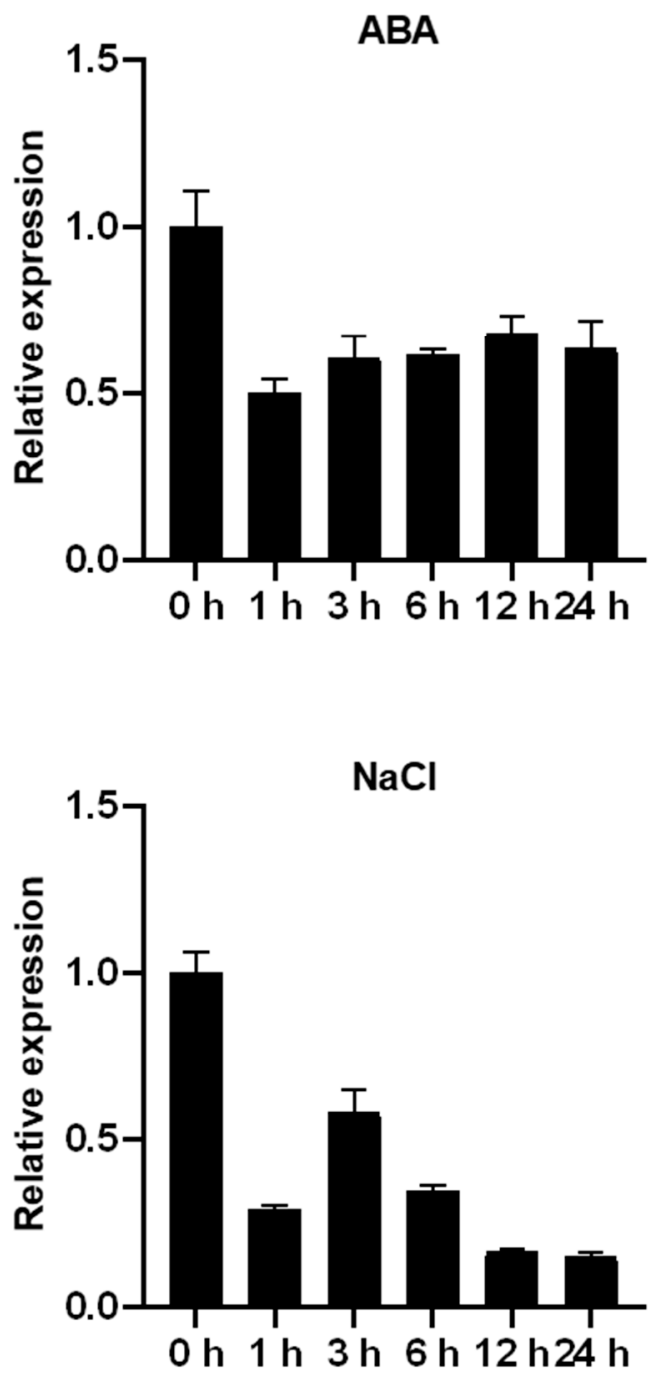

Figure 3. Expression patterns of $\mathrm{ZmHsf08.} \mathrm{(A)} \mathrm{RT-qPCR} \mathrm{analysis} \mathrm{of} \mathrm{ZmHsf08}$ expression in six tissues (roots, stem, leaves, cornsilk, tassels and bract). (B-D) Expression analysis of $\mathrm{ZmHsf08}$ under ABA, PEG, and NaCl treatments. The three-leaf stage seedlings were treated with ABA, PEG, and $\mathrm{NaCl}$, and the expression levels of $\mathrm{ZmHsf08}$ were detected by RT-qPCR. Bars represent means $\pm \mathrm{SD}$ ( $n=3$ repeats).

To determine whether $\mathrm{ZmHsf08}$ is involved in plant salt stress tolerance, we performed a salt stress tolerance assay in transgenic lines and wild-type (WT) plants. Before stress treatments, there was no obvious difference in phenotype between the transgenic lines and WT plants. After being subjected to $200 \mathrm{mM} \mathrm{NaCl}$ treatment for 2 weeks, the most leaves of WT plants remained green, whereas the leaves of OE8-1 and OE8-2 plants were severely wilted (Figure 4A). Meanwhile, the survival rates of OE8-1 and OE8-2 plants were significantly decreased compared with the WT (Figure 4C). In addition, ZmHsfo8 expression in the transgenic lines OE8-1 and OE8-2 was downregulated under stress conditions (Supplementary Figure S1). We also analyzed the physiological responses to salt stress in the WT plants and two transgenic maize lines. DAB staining showed that significantly more reddish-brown precipitate accumulated in the leaves of transgenic plants than that of WT under salt stress treatment, indicating higher $\mathrm{H}_{2} \mathrm{O}_{2}$ levels in transgenic lines (Figure 4D). Additionally, the contents of MDA were measured in WT and transgenic maize seedlings before and after salt stress treatment. As shown in Figure 4E, the accumulation of MDA in transgenic lines increased significantly compared with that in WT plants under both control and salt conditions. These results indicated that the overexpression of $\mathrm{ZmHsf08}$ in maize enhances sensitivity to salt stress. 
A
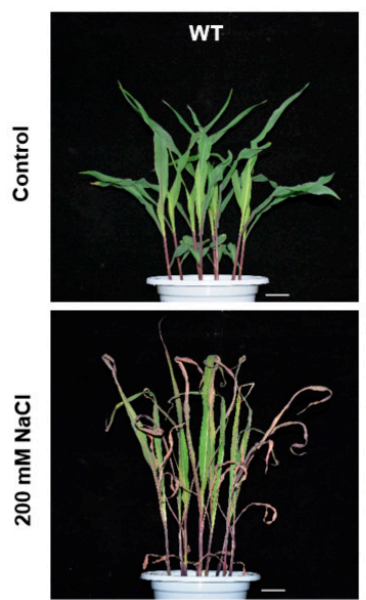

B

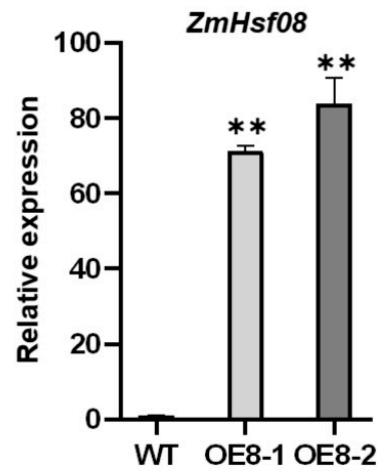

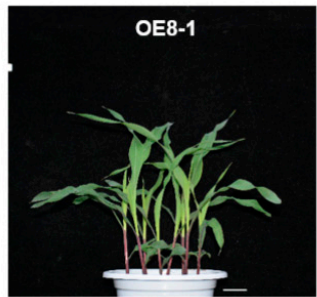
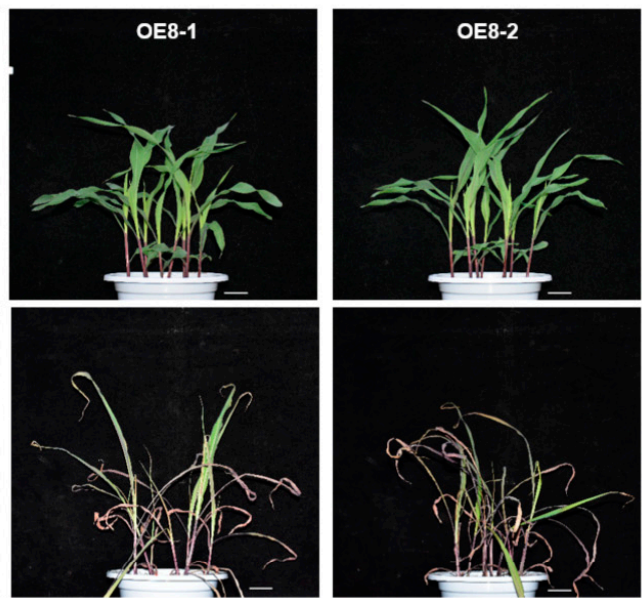

C

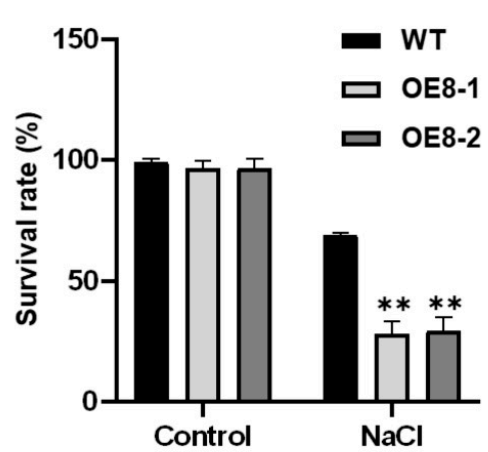

D

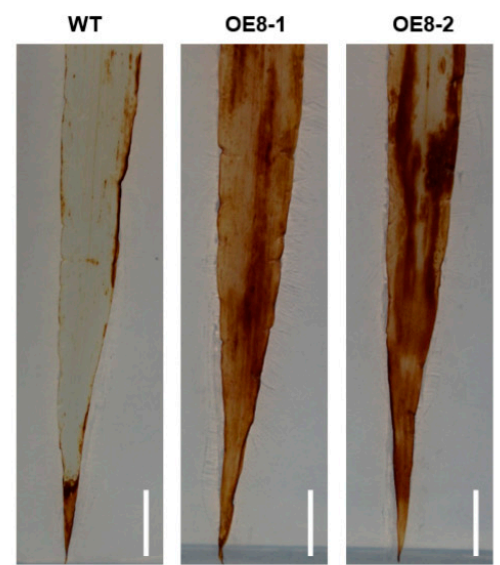

E

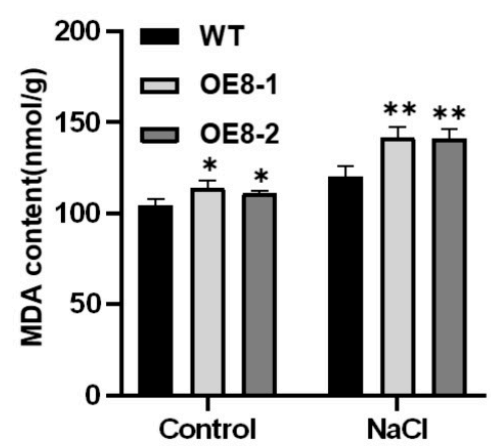

Figure 4. Salt stress tolerance test in the wild-type (WT) and ZmHsf08-overexpressing plants. (A) The phenotypes of WT and $\mathrm{ZmHsf08-overexpressing} \mathrm{plants} \mathrm{under} \mathrm{NaCl}$ treatment. Three-leaf stage maize seedlings were treated with $200 \mathrm{mM}$ $\mathrm{NaCl}$ for 2 weeks; the pictures were obtained before or after treatment. (B) Expression levels of ZmHsf08 in transgenic maize seedlings were examined by RT-qPCR. (C) Survival rate of WT and ZmHsf08 transgenic plants after treatment with $200 \mathrm{mM}$ $\mathrm{NaCl}$ for 2 weeks. (D) Diaminobenzidine (DAB) staining of the maize leaves after $\mathrm{NaCl}$ treatment for 7 days. Bar $=1 \mathrm{~cm}$. (E) Malondialdehyde (MDA) content of WT and ZmHsf08 transgenic plants under normal conditions and salt treatment for 7 days. Values are means \pm SD. Bars represent means \pm SD ( $n=3$ repeats). Significant differences (Student's $t$ test): ${ }^{*}, p<0.05,{ }^{* *}, p<0.01$.

To confirm the role of $\mathrm{ZmHsf08}$ in maize drought response, we performed a drought stress experiment in soil by withholding water. After drought for 2 weeks, the $\mathrm{ZmHsf08-}$ overexpressing plants exhibited more severe wilt phenotype than WT plants, and almost all their leaves were severely dehydrated and curled (Figure 5A). To examine whether the dehydration phenotype could be recovered, we further performed a re-watering experiment. After re-watering for 3 days, the WT plants had grown fresh new leaves, and about $75 \%$ of them showed growth recovery; however, only about $20 \%$ of the over-expressing plants could recover growth after re-watering (Figure 5A,B). In consistency with the phenotype, the leaves of $\mathrm{ZmHsf08}$ transgenic plants accumulated higher $\mathrm{H}_{2} \mathrm{O}_{2}$ levels and had higher MDA content compared to WT plants, indicating that more damage was induced in transgenic plants (Figure 5C,D). Additionally, we performed a water loss assay of detached leaves using WT and $\mathrm{ZmHsfo8-overexpressing} \mathrm{plants.} \mathrm{The} \mathrm{rate} \mathrm{of} \mathrm{water} \mathrm{loss} \mathrm{from} \mathrm{the}$ transgenic plants was faster than that from the WT plants, suggesting that overexpression of $\mathrm{ZmHsf08}$ promoted water loss of leaves (Figure 5E). These findings demonstrated that overexpression of $\mathrm{ZmHsf08}$ results in decreased drought stress tolerance in maize. 
A
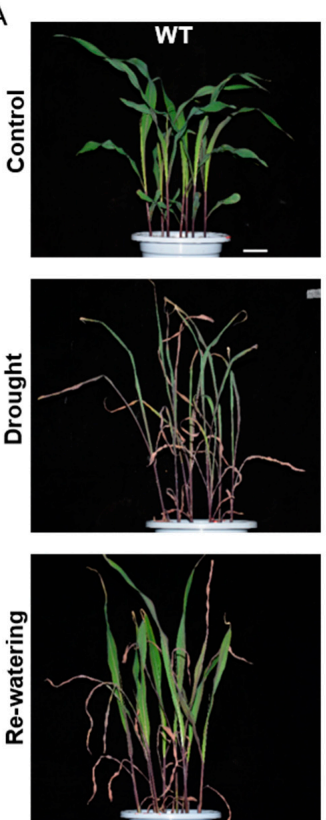

D

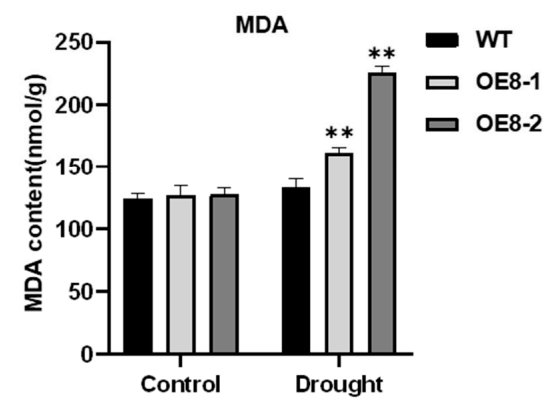

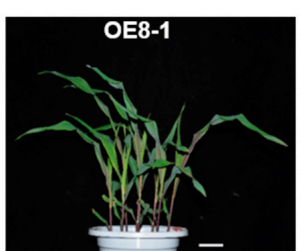
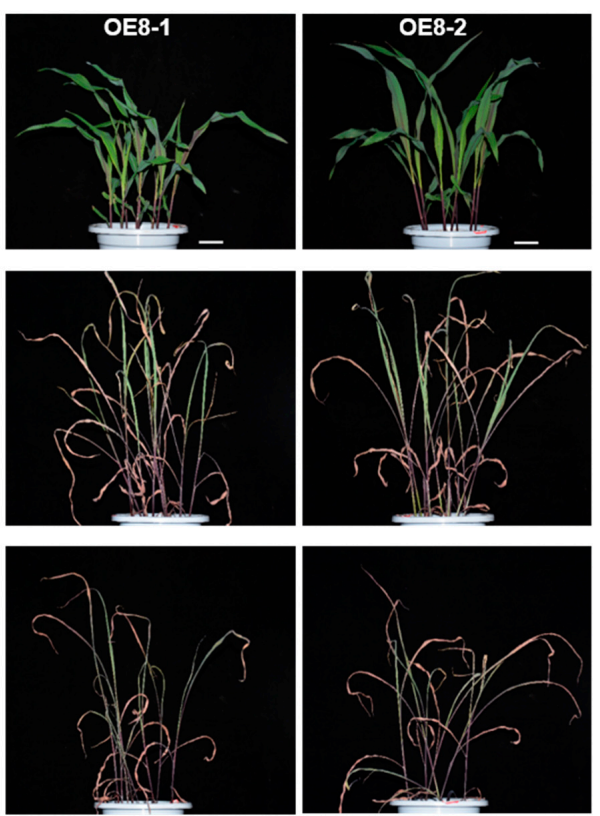

$\mathrm{E}$

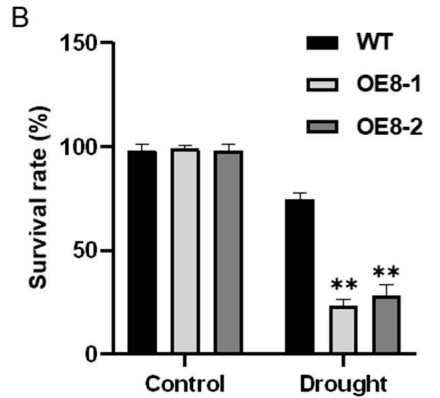

C

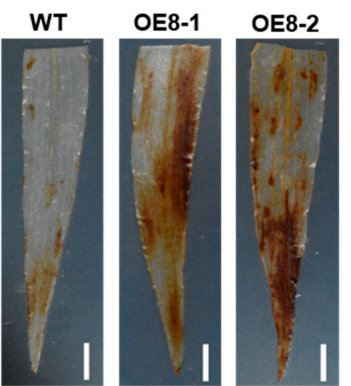

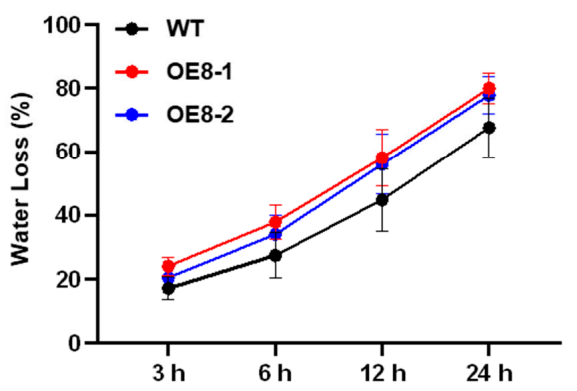

Figure 5. Drought stress tolerance test in the WT and ZmHsf08-overexpressing plants. (A) The phenotypes of WT and $\mathrm{ZmHsf08-overexpressing} \mathrm{plants} \mathrm{under} \mathrm{drought} \mathrm{stress} \mathrm{in} \mathrm{soil.} \mathrm{Three-leaf} \mathrm{stage} \mathrm{maize} \mathrm{seedlings} \mathrm{were} \mathrm{withheld} \mathrm{water} \mathrm{for}$ 2 weeks and re-watered for 3 days. The pictures were obtained under normal, drought, and re-watering conditions. (B) Survival rate of WT and transgenic plants after re-watering for 3 days. (C) DAB staining of the maize leaves. The WT and transgenic plants were withheld water for 7 days, and then the leaves were collected. Bar $=1 \mathrm{~cm}$. (D) MDA content of WT and transgenic plants under normal condition and drought treatment for 7 days. (E) Water loss rate of the detached leaves of WT and transgenic plants. The leaves of three-leaf stage maize seedlings were taken, and loss of weight was measured at the indicated time point. Values are means \pm SD. Bars represent means $\pm \operatorname{SD}(n=3$ repeats). Significant differences (Student's $t$ test): ${ }^{* *}, p<0.01$.

\subsection{Expression of Stress-Responsive Genes Were Altered in ZmHsf08-Overexpressing Plants}

To further understand the regulation mechanisms of $\mathrm{ZmHsf08}$ in salt and drought stress responses, we assayed the expression levels of several known stress-responsive genes in WT and transgenic plants under control and stress conditions, such as ZmDREB2A (dehydration-responsive element-binding protein 2A), ZmNCED (9-cis-epoxycarotenoid dioxygenase), ZmERD1 (early responsive to dehydration 1), ZmRD20 (RESPONSIVE TO DESICCATION 20), and ZmRAB18 (RESPONSIVE TO ABA 18). The RD20 gene is often used as a stress marker gene and played an important role in plant drought tolerance [52,53]. Overexpression of LEA (LATE EMBROGENESIS ABUNDANT PROTEIN), which encodes a highly hydrophilic protein, enhances plant tolerance to drought stress [54,55]. Constitutive expression of a vacuolar $\mathrm{Na}^{+} / \mathrm{H}^{+}$antiporter gene, AtNHX3 (SODIUM/HYDROGEN EXCHANGER3), in sugar beet (Beta vulgaris) improved high salinity tolerance in transgenic plants [56]. NCED and ZEP (zeaxanthin epoxidase) are key enzymes for ABA biosynthesis, and overexpression of the two genes enhanced abiotic tolerance in transgenic plants $[57,58]$. 
Before salt stress treatment, the expression levels of the analyzed stress-responsive genes, including ZmDREB2A, ZmABF2(ABRE-BINDING FACTOR 2), ZmZEP, and ZmNHX3, were suppressed in transgenic plants compared with WT plants, while ZmNCED, ZmERD1, $Z m D R 20$, and $Z m R A B 18$ expression levels in transgenic plants were higher than in WT plants. However, the expression levels of most analyzed genes (ZmDREB2A, ZmERD1, $Z m N H X 3, Z m R A B 18$, and ZmLEA2) were obviously decreased in transgenic plants compared with that in WT plants under salt stress (Figure 6). There was a similar pattern of repressed expression of stress-responsive genes in transgenic plants following drought stress treatment (Figure 7). The expression levels of the analyzed genes (except ZmDREB2A) were higher in transgenic plants compared with WT plants under control conditions to some extent; however, under drought stress, the expression levels of these genes in transgenic plants also dramatically decreased compared with those in WT plants (Figure 7). These results suggested that $\mathrm{ZmHsf08}$ plays a negative role in regulating these stress/ABAresponsive genes under salt and drought stresses.

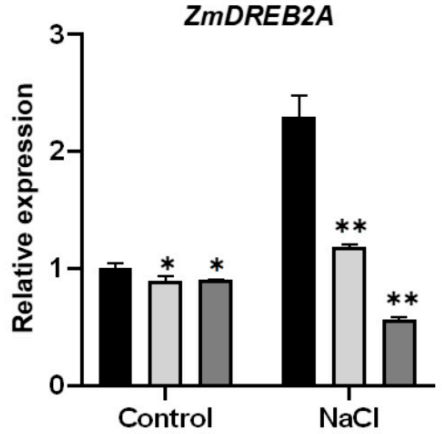

ZmRD20
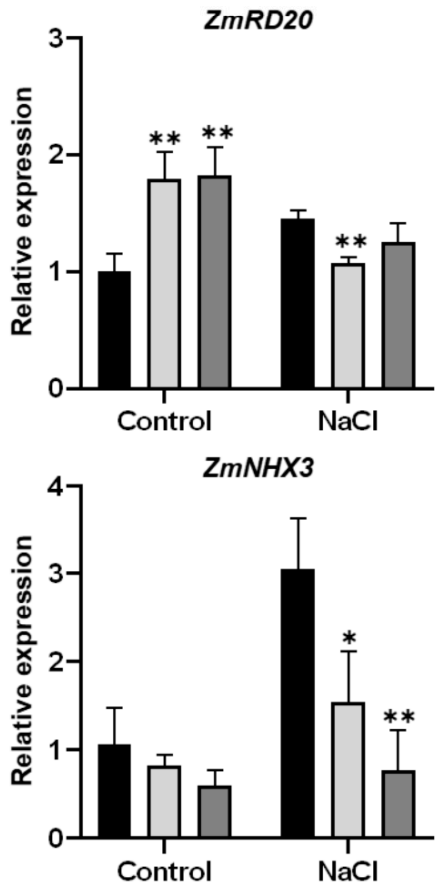

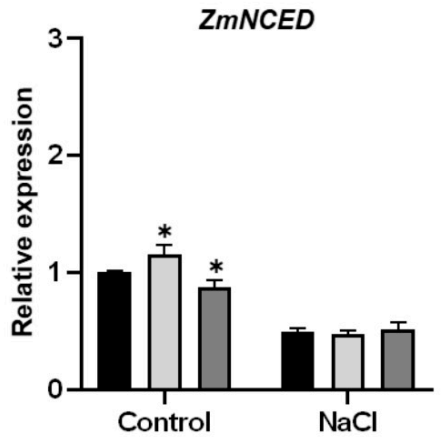

ZmABF2
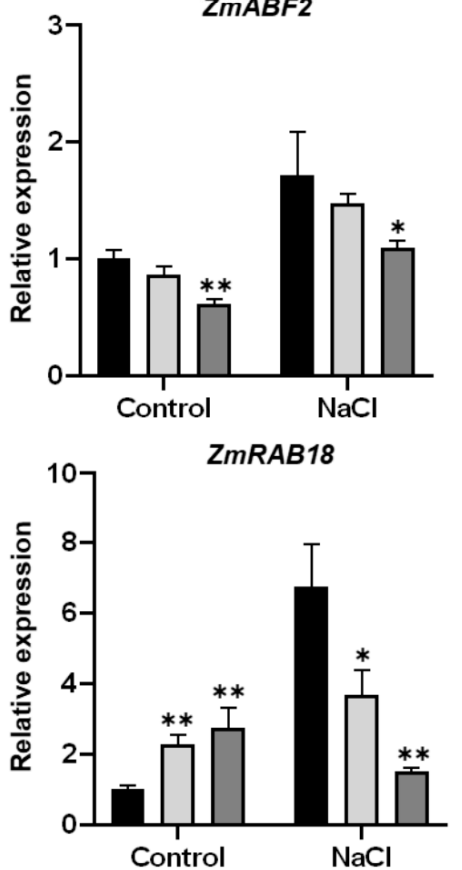

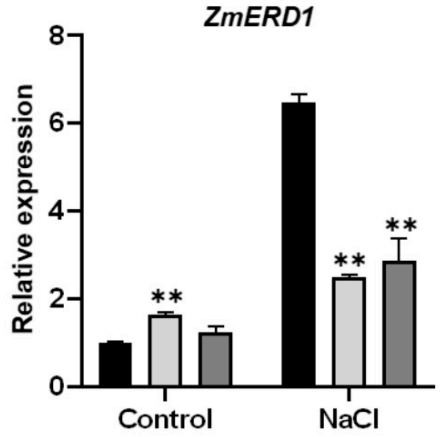

ZmZEP

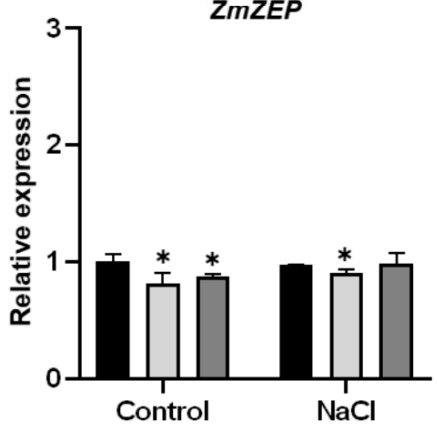

ZmLEA2

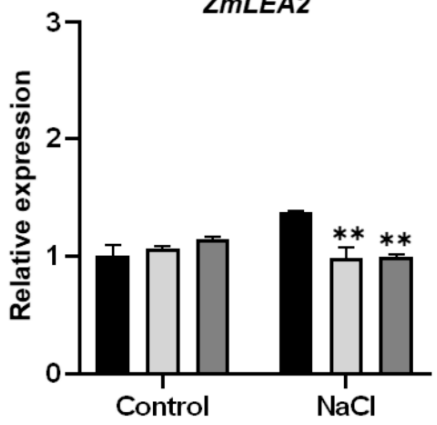

WT

OE8-1

OE8-2

Figure 6. Expression patterns of stress-responsive genes in WT and ZmHsf08-overexpressing plants under normal condition and $\mathrm{NaCl}$ treatment. Three-leaf stage maize seedlings were treated with $200 \mathrm{mM} \mathrm{NaCl}$ for 7 days. The expression levels of stress-responsive genes during salt stress were analyzed by RT-qPCR. Values are means $\pm \mathrm{SD}$. Bars represent means $\pm \mathrm{SD}$ ( $n=3$ repeats). Significant differences (Student's $t$ test): ${ }^{*}, p<0.05,{ }^{* *}, p<0.01$. 

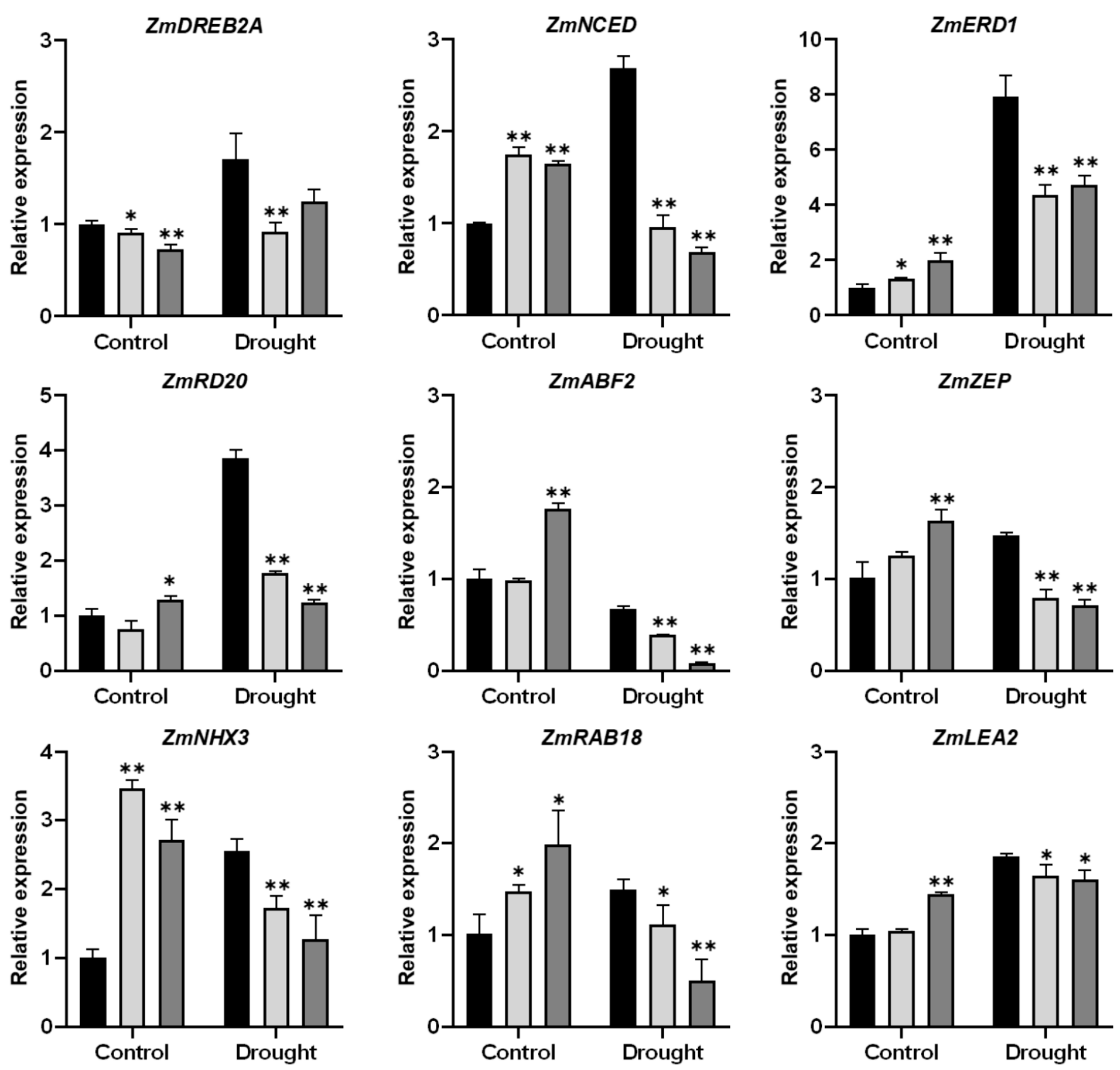

WT

OE8-1

OE8-2

Figure 7. Expression levels of stress-responsive genes in WT and $\mathrm{ZmHsf08-overexpressing} \mathrm{plants} \mathrm{under} \mathrm{normal} \mathrm{condition}$ and drought treatment. Three-leaf stage maize seedlings were withheld water for 7 days. The expression levels of stressresponsive genes during drought stress were analyzed by RT-qPCR. Values are means $\pm \mathrm{SD}$. Bars represent means \pm SD $\left(n=3\right.$ repeats). Significant differences (Student's $t$ test): ${ }^{*}, p<0.05,{ }^{* *}, p<0.01$.

\subsection{Homomeric Interaction of $\mathrm{ZmHsf08}$}

Since $\mathrm{ZmHsf08}$ is an HSFB protein and has a core BRD sequence, we speculated that it would have no transactivation activity. To confirm this hypothesis, we performed a yeast transactivation assay. The full-length $\mathrm{ZmHsf08} \mathrm{CDS}$ was cloned into the pGBK-T7 vector, and the recombinant construct was transformed into yeast AH109 (Figure 8A). As expected, the results showed that $\mathrm{ZmHsf08}$ has no transcriptional activity in yeast (Figure $8 \mathrm{~B}$ ). 


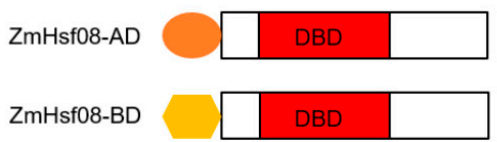

C

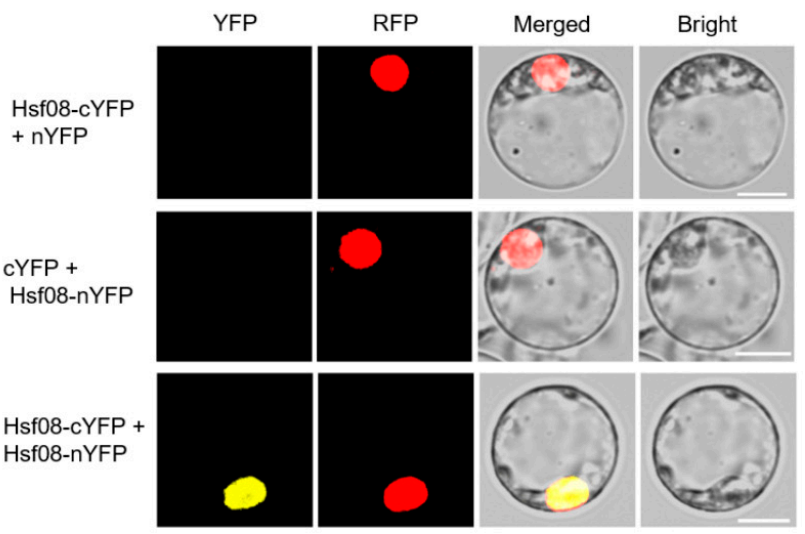

B

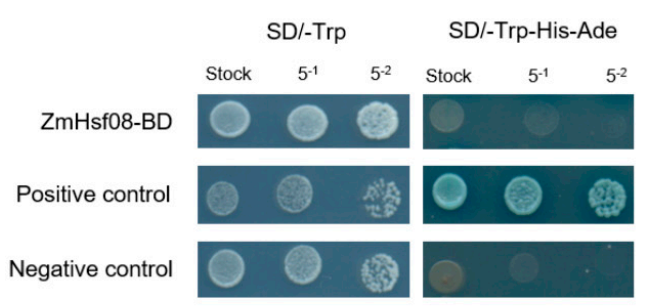

D

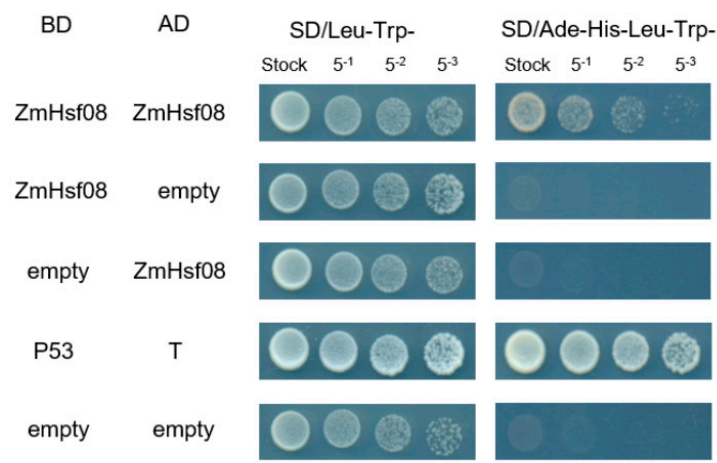

Figure 8. Homodimerization of ZmHsf08. (A) Schematic representation of the structures of ZmHsf08-AD and ZmHsf08-BD. (B) The transcriptional activation activity assay in yeast cells. (C) Bimolecular fluorescence complementation (BiFC) assay of the homodimerization of $\mathrm{ZmHsf08}$ in maize protoplasts. Different combinations of the nYFP and cYFP fusion constructs were cotransformed into maize protoplasts, and the fluorescence signals were examined with a confocal microscope. (D) Yeast two-hybrid $(\mathrm{Y} 2 \mathrm{H})$ analysis of the self-interaction of $\mathrm{ZmHsf08.} \mathrm{AD,} \mathrm{GAL4} \mathrm{activation} \mathrm{domain;} \mathrm{BD,} \mathrm{GAL4} \mathrm{DNA} \mathrm{binding}$ domain; Protein-protein interactions were examined by yeast cell growth on the SD/-Leu/-Trp/-His/-Ade plate.

A previous study suggested that HsfBs (HsfB1 and HsfB2b) can form homologous interactions, and are involved in the regulatory networks of stress responses through forming complexes with other proteins [47]. To determine if $\mathrm{ZmHsf08} \mathrm{forms} \mathrm{homodimers,}$ we performed a bimolecular fluorescence complementation (BiFC) assay. It was observed that $\mathrm{ZmHsf08}$ interacted with itself; in addition, the homodimers of $\mathrm{ZmHsf08}$ were located in the nucleus (Figure $8 \mathrm{C}$ ). The interactions were further examined by a yeast two-hybrid (Y2H) assay. The full-length $\mathrm{ZmHsf08} \mathrm{CDS} \mathrm{was} \mathrm{cloned} \mathrm{into} \mathrm{the} \mathrm{pGAD-T7} \mathrm{and} \mathrm{pGBK-T7}$

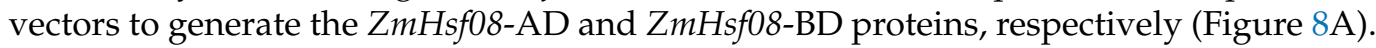
The ZmHsf08-AD was cotransformed into yeast with ZmHsf08-BD; as we expected, the $\mathrm{Y} 2 \mathrm{H}$ assay also showed that $\mathrm{ZmHsf08}$ interacts with itself (Figure 8D).

\section{Discussion}

Abiotic stress, including salt and drought stress, has adverse effects on the growth and yield of crop plants. Maize, an important crop for livestock and humans, is threatened by salt and drought stress. It is known that transcription factors (TFs) play important roles in mediating abiotic stress responses by regulating the expression of stress-responsive genes $[13,19]$. Among these TFs, HSF TFs are an important family of regulatory proteins with diversified functions. In recent years, the functions of HSF genes involved in diverse abiotic stress responses have been reported in soybean, tomato, Arabidopsis, wheat, and rice $[22,27,29,39,41,46]$. In this study, we identified a class B HSF gene, ZmHsf08, from maize and analyzed its functions in response to salt and drought stress.

$\mathrm{ZmHsf08}$ is a typical HSF transcription factor with conserved domains, including a DNA binding domain (DBD), an intermediate OD (HR-A/B) region, one nuclear localization signal (NLS), and one nuclear export signal (NES). The sequence analysis revealed that $\mathrm{ZmHsf08}$ had a close homologous relationship with HsfB1 proteins from other species (Figure 1B), suggesting that ZmHsf08 belongs to the HsfB1 subgroup. We found that $\mathrm{ZmHsf08}$ contained the NLS sequence (KKRR), which suggests a putative nuclear targeting 


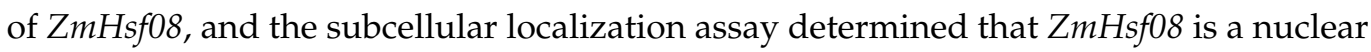
localized protein (Figure 2). In addition, $\mathrm{ZmHsf08}$ had no transcriptional activity in yeast as a result of the conserved B3 repression domain (BRD) at the C-terminus of $\mathrm{ZmHsf08}$ sequence (Figure 1B), which is consistent with the features of class B HSFs [52,53]. These results demonstrated that $\mathrm{ZmHsf08}$ is a novel $\mathrm{HsfB}$ gene in maize.

Many studies have reported that the $H s f$ genes are involved in salt and drought stress responses. For example, the Arabidopsis plants overexpressing AtHsfA6a and AtHsfA7b exhibited enhanced tolerance against salt and drought stresses [42,54]. The ectopic expression of tomato HSFA3 in Arabidopsis increased salt hypersensitivity in transgenic plants [37]. The overexpression of OsHsfA7 in rice demonstrated that OsHsfA7 acted as a positive regulator in salt and drought tolerance [41]. On the contrary, OsHsfB2b functioned as a negative regulator in response to salt and drought stresses in rice [46]. However, the biological functions of most $H s f B$ proteins in maize remains largely elusive. Interestingly, the expression profiling revealed that $\mathrm{ZmHsf08}$ expression was down-regulated after treatment with $\mathrm{PEG}, \mathrm{NaCl}$, and $\mathrm{ABA}$ (Figure $2 \mathrm{~B}-\mathrm{D}$ ), suggesting that $\mathrm{ZmHsf08}$ may play a role in abiotic-stress responses in maize.

Our study demonstrated that $\mathrm{ZmHsf08}$ is involved in salt and drought stress response. Overexpression of $\mathrm{ZmHsf08}$ in maize increased sensitivity to salt and drought stress, with worse growth performance and a significantly decreased survival rate under stress treatments (Figures 4 and 5). Salt and drought stress impose osmotic stress, which leads to the excess generation of reactive oxygen species (ROS), resulting in damage to plant cellular physiology and biochemistry $[55,56] . \mathrm{H}_{2} \mathrm{O}_{2}$ and $\mathrm{O}^{-2}$ are two ROS indices that are involved in abiotic stress signaling. Therefore, the accumulation of $\mathrm{H}_{2} \mathrm{O}_{2}$ was revealed using diaminobenzidine $(\mathrm{DAB})$ staining under normal and stress conditions using maize leaves. In our study, the accumulation of $\mathrm{H}_{2} \mathrm{O}_{2}$ contents was obviously increased in $\mathrm{ZmHsf08}$ transgenic plants compared to WT plants under salt and drought stress conditions (Figures $4 \mathrm{D}$ and $5 \mathrm{C}$ ), implying that the overexpressing $\mathrm{ZmHsf08}$ in maize apparently aggravated oxidative damage by generating high ROS levels during stress treatments. This result was further confirmed by malonaldehyde (MDA) content, which is an indicator of lipid peroxidation and cell membrane damage. The MDA level in the transgenic plants was significantly higher than in WT plants in response to drought and salt stress treatments (Figures $4 \mathrm{E}$ and $5 \mathrm{D}$ ), indicating that $\mathrm{ZmHsf08}$ increases cell membrane injury under stress

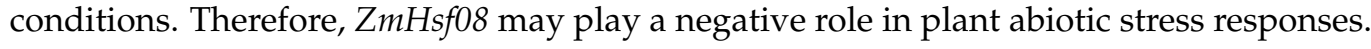

To adapt to various abiotic stresses, especially salt and drought stresses, plants develop different response strategies, including modulation of the expression of stress-responsive genes [4,12]. In this study, we found that the expression levels of stress-responsive genes including ZmERD1, ZmRD20, ZmRAB18, ZmNCED, ZmNHX3, ZmZEP, and Zm$L E A$ were higher in transgenic plants than those in WT plants under control conditions (Figures 6 and 7). However, under drought stress, the expression levels of these stressresponsive genes were markedly decreased in transgenic plants compared with those in WT plants (Figure 7). Similarly, the stress-responsive genes ZmERD1, ZmRD20, ZmRAB18, Zm$N C E D$, and ZmLEA also showed decreased transcript levels in transgenic plants compared with WT plants under salt conditions (Figure 6). These results indicated that $\mathrm{ZmHsf08}$ negatively regulates salt and drought stress responses, perhaps through the repressed expression of stress-responsive genes. It was reported that $H s f B s$ have the capability to form homodimers in vivo and may be involved in complex regulatory networks of signaling processes and stress responses. The BiFC and $\mathrm{Y} 2 \mathrm{H}$ assays indicated that $\mathrm{ZmHsf08}$ forms homodimer in vivo. Therefore, we speculate that the $\mathrm{ZmHsf08}$ homodimers alone or interacting with other TFs to regulate the expression of stress-responsive genes in stress responses. This hypothesis needs to be studied in depth in the future.

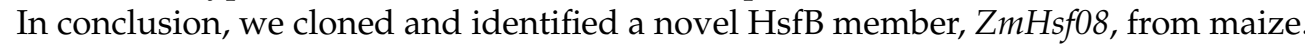
Overexpression of $\mathrm{ZmHsf08}$ in maize resulted in increased sensitivity to salt and drought stresses, which were associated with higher ROS levels and higher MDA contents. Furthermore, RT-qPCR analyses indicated that $\mathrm{ZmHsf08}$ negatively regulates the expression of 
stress/ABA-responsive genes in response to salt and drought stresses (Figures 6 and 7). Our findings provide new information to better understand the function of $\mathrm{ZmHsf08}$ in plant abiotic stress responses.

\section{Materials and Methods}

\subsection{Plant Materials and Growth Conditions}

The maize inbred line B73 (seeds stored in our laboratory) was used for ZmHsfo8 gene cloning and expression analysis. The maize inbred line KN5585 (WT) and transgenic $\mathrm{ZmHsf08}$ plants were provided by Weimi Biotech Co., Ltd. and used for salt and drought stress experiments. Maize seeds were surface sterilized and germinated at $28^{\circ} \mathrm{C}$ for 3 days (dark). Then, seedlings with primary root were sown in pots with soil and grown in a greenhouse $\left(14 \mathrm{~h} / 10 \mathrm{~h}\right.$ of light/dark; $30^{\circ} \mathrm{C} / 25^{\circ} \mathrm{C}$ of day/night) until they reached the three-leaf stage.

\subsection{Sequence Alignment and Phylogenetic Analysis}

Sequences of $\mathrm{ZmHsf08}$ and other HsfB members from different plant species (Oryza sativa, Sorghum bicolor, Brachypodium distachyon, and Arabidopsis thaliana) were obtained from NCBI (https: / / www.ncbi.nlm.nih.gov/) (accessed on 6 May 2021). The amino acid sequences of different HsfB1 proteins were aligned by ClustalX software. The conserved motifs of these proteins, including DNA binding domain (DBD), oligomerization domain (OD), nuclear export signal (NES), and nuclear location signal (NLS), were defined by SMART (http://smart.embl-heidelberg.de/) (accessed on 8 January2021).

A phylogenetic tree was constructed using the neighbor-joining method in MEGA 7.0. The neighbor-joining method was performed with 1000 bootstrap replicates.

\subsection{Expression Analysis of $\mathrm{ZmHsf08}$}

The roots, stems, and leaves form seedlings of B73 at the three-leaf stage, and immature cornsilk, tassels, and bract from B73 plants in the V13 stage were sampled for tissue-specific expression analysis. For stress treatments, the B73 seedlings at the three-leaf stage were either watered with $20 \%(w / v)$ PEG6000, watered with $200 \mathrm{mM} \mathrm{NaCl}$, or watered with $0.1 \mathrm{mM}$ ABA. The leaves of seedlings under each treatment were collected at the designated time points $(0,1,3,6,12$, and $24 \mathrm{~h})$, and the samples were immediately frozen in liquid nitrogen. Total RNA was extracted using Total RNA Extraction Reagent (Vazyme), and cDNA was synthesized using HiScript III RT SuperMix (Vazyme). RT-qPCR was performed using AceQ qPCR SYBR Green Master Mix (Vazyme) on the Thermo Scientific PikoReal 96 RT-PCR instrument. ZmGAPDH was used as internal control for maize. All the primers used for RT-qPCR are listed in Supplementary Table S2.

\subsection{Subcellular Localization}

The coding sequences (CDS) of $\mathrm{ZmHsf08}$ without or with a stop codon were cloned by PCR and then constructed into p1305-GFP and PMDC43 vectors (stored in our laboratory), respectively, for subcellular localization. The primers are shown in Supplementary Table S1. The recombined vectors $\mathrm{ZmHsf08-GFP}$ and GFP-ZmHsf08, or the empty vectors p1305-GFP and PMDC43, were transformed into the maize protoplasts according to the previous description $[59,60]$. The RFP vector, a marker for nucleus localization, was cotransformed with these constructs into maize protoplasts. After being cultured in multi-well plates for $18-24 \mathrm{~h}$ in the dark, the protoplasts were observed under a confocal laser scanning microscope (LSM710; Zeiss).

\subsection{Transactivation Activity and Two-Hybrid Assays in Yeast}

The full-length CDS of ZmHsf08 was cloned into a pGAD-T7 or pGBK-T7 vector,

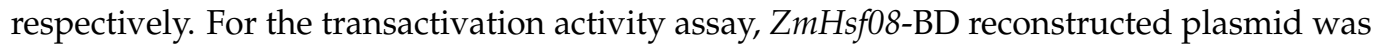
transformed into the yeast strain $\mathrm{AH} 109$. In addition, the transcriptional activation activity was examined by spot assay and X-gal staining. For the two-hybrid assays, recombined vec- 
tors were transformed in pairs in the yeast Y2HGold cells. The interaction between the two proteins was examined by spot assay. The primers are listed in Supplementary Table S1.

\subsection{BiFC Assay}

The coding sequence of $\mathrm{ZmHsf08}$ without a stop codon was cloned into pUC-SPYCE and pUC-SPYNE vectors, respectively, generating Hsf08-cYFP and Hsf08-nYFP constructs. The primers used in the assay are listed in Supplementary Table S1. Different combinations of cYFP and nYFP constructs were cotransformed with RFP into maize protoplasts. The isolation and transformation of maize protoplasts were performed according to the previous protocol $[59,60]$. The protoplasts were cultured for $18-24 \mathrm{~h}$ in the dark, and then were observed under a confocal laser scanning microscope (LSM710; Zeiss).

\subsection{Salt and Drought Stress Experiment}

For the salt stress tolerance test, the three-leaf stage maize seedlings (the transgenic lines and the WT plants) were irrigated with $200 \mathrm{mM} \mathrm{NaCl}$ solution for two weeks. Then, the phenotypes and survival rates of plants were measured.

For drought stress tolerance test, the WT and transgenic plants seedlings at three-leaf stage did not receive watering for 14 days until the plants withered. After drought for 14 days and re-watering for 3 days, the recovered conditions of the WT and transgenic lines were recorded. The survival rates of plants were measured after re-watering for 3 days under normal conditions.

\subsection{DAB Staining and MDA Content Measurement}

After salt and drought treatment for 10 days, leaves of the WT and transgenic plants were stained with diaminobenzidine (DAB) to detect the accumulation of $\mathrm{H}_{2} \mathrm{O}_{2}$. Leaves of the same location of maize seedlings were collected and immersed in DAB solution $(1 \mathrm{mg} / \mathrm{mL}, \mathrm{pH} 3.8)$. All the samples were incubated overnight at room temperature in darkness. The leaves were then bleached by boiling in bleach solution (ethanol: acetic acid: glycerol, 3:1:1, $v / v / v$ ) for $20 \mathrm{~min}$ to remove the chlorophyll before imaging.

The three-leaf stage seedlings of WT and transgenic plants were treated with $200 \mathrm{mM}$ $\mathrm{NaCl}$ or watering was stopped for 10 days and then the leaves were collected. The MDA was extracted from $0.1 \mathrm{~g}$ maize leaf samples and measured according to the protocol from NanJing JianCheng Bioengineering Institute.

Supplementary Materials: The following are available online at https:/ / www.mdpi.com/article/10.3 390/ijms222111922/s1.

Author Contributions: Investigation, J.W. and L.C.; Data curation, J.W. and Y.L.; Funding acquisition, B.C. and H.J.; Writing—original draft, J.W.; Writing—review and editing, J.W. and W.S. All authors have read and agreed to the published version of the manuscript.

Funding: This research was funded by the National Natural Science Foundation of China, grant number 31771805 .

Institutional Review Board Statement: Not applicable.

Informed Consent Statement: Not applicable.

Data Availability Statement: The data presented in this study are available on request from the corresponding author.

Conflicts of Interest: The authors declare no conflict of interest. 


\section{References}

1. Morton, M.J.L.; Awlia, M.; Al-Tamimi, N.; Saade, S.; Pailles, Y.; Negrao, S.; Tester, M. Salt stress under the scalpel-Dissecting the genetics of salt tolerance. Plant J. 2019, 97, 148-163. [CrossRef]

2. Sallam, A.; Alqudah, A.M.; Dawood, M.F.A.; Baenziger, P.S.; Borner, A. Drought Stress Tolerance in Wheat and Barley: Advances in Physiology, Breeding and Genetics Research. Int. J. Mol. Sci. 2019, 20, 3137. [CrossRef]

3. Gill, S.S.; Tuteja, N. Reactive oxygen species and antioxidant machinery in abiotic stress tolerance in crop plants. Plant Physiol. Biochem. 2010, 48, 909-930. [CrossRef] [PubMed]

4. Landi, S.; Hausman, J.F.; Guerriero, G.; Esposito, S. Poaceae vs. Abiotic Stress: Focus on Drought and Salt Stress, Recent Insights and Perspectives. Front. Plant Sci. 2017, 8, 1214. [CrossRef] [PubMed]

5. Zou, J.J.; Wei, F.J.; Wang, C.; Wu, J.J.; Ratnasekera, D.; Liu, W.X.; Wu, W.H. Arabidopsis calcium-dependent protein kinase CPK10 functions in abscisic acid- and Ca2+-mediated stomatal regulation in response to drought stress. Plant Physiol. 2010, 154, 1232-1243. [CrossRef] [PubMed]

6. Yang, Z.J.; Wang, C.W.; Xue, Y.; Liu, X.; Chen, S.; Song, C.P.; Yang, Y.Q.; Guo, Y. Calcium-activated 14-3-3 proteins as a molecular switch in salt stress tolerance. Nat. Commun. 2019, 10, 1199. [CrossRef]

7. Balzergue, C.; Dartevelle, T.; Godon, C.; Laugier, E.; Meisrimler, C.; Teulon, J.M.; Creff, A.; Bissler, M.; Brouchoud, C.; Hagege, A.; et al. Low phosphate activates STOP1-ALMT1 to rapidly inhibit root cell elongation. Nat. Commun. 2017, 8 , 15300. [CrossRef] [PubMed]

8. Busoms, S.; Paajanen, P.; Marburger, S.; Bray, S.; Huang, X.Y.; Poschenrieder, C.; Yant, L.; Salt, D.E. Fluctuating selection on migrant adaptive sodium transporter alleles in coastal Arabidopsis thaliana. Proc. Natl. Acad. Sci. USA 2018, 115, E12443-E12452. [CrossRef] [PubMed]

9. Zang, X.; Geng, X.; Wang, F.; Liu, Z.; Zhang, L.; Zhao, Y.; Tian, X.; Ni, Z.; Yao, Y.; Xin, M.; et al. Overexpression of wheat ferritin gene TaFER-5B enhances tolerance to heat stress and other abiotic stresses associated with the ROS scavenging. BMC Plant Biol. 2017, 17, 14. [CrossRef]

10. Yoshida, T.; Mogami, J.; Yamaguchi-Shinozaki, K. ABA-dependent and ABA-independent signaling in response to osmotic stress in plants. Curr. Opin. Plant Biol. 2014, 21, 133-139. [CrossRef]

11. Sah, S.K.; Reddy, K.R.; Li, J. Abscisic Acid and Abiotic Stress Tolerance in Crop Plants. Front. Plant Sci. $2016,7,571$. [CrossRef] [PubMed]

12. Golldack, D.; Luking, I.; Yang, O. Plant tolerance to drought and salinity: Stress regulating transcription factors and their functional significance in the cellular transcriptional network. Plant Cell Rep. 2011, 30, 1383-1391. [CrossRef]

13. Singh, D.; Laxmi, A. Transcriptional regulation of drought response: A tortuous network of transcriptional factors. Front. Plant Sci. 2015, 6, 895. [CrossRef] [PubMed]

14. Sarkar, T.; Thankappan, R.; Mishra, G.P.; Nawade, B.D. Advances in the development and use of DREB for improved abiotic stress tolerance in transgenic crop plants. Physiol. Mol. Biol. Plants 2019, 25, 1323-1334. [CrossRef]

15. Song, H.; Wang, P.F.; Hou, L.; Zhao, S.Z.; Zhao, C.Z.; Xia, H.; Li, P.C.; Zhang, Y.; Bian, X.T.; Wang, X.J. Global Analysis of WRKY Genes and Their Response to Dehydration and Salt Stress in Soybean. Front. Plant Sci. 2016, 7, 9. [CrossRef]

16. Wang, X.; Niu, Y.; Zheng, Y. Multiple Functions of MYB Transcription Factors in Abiotic Stress Responses. Int. J. Mol. Sci. 2021, 22, 6125. [CrossRef]

17. Ma, H.; Liu, C.; Li, Z.; Ran, Q.; Xie, G.; Wang, B.; Fang, S.; Chu, J.; Zhang, J. ZmbZIP4 Contributes to Stress Resistance in Maize by Regulating ABA Synthesis and Root Development. Plant Physiol. 2018, 178, 753-770. [CrossRef]

18. Guo, M.; Liu, J.H.; Ma, X.; Luo, D.X.; Gong, Z.H.; Lu, M.H. The Plant Heat Stress Transcription Factors (HSFs): Structure, Regulation, and Function in Response to Abiotic Stresses. Front. Plant Sci. 2016, 7, 114. [CrossRef]

19. Wang, H.; Wang, H.; Shao, H.; Tang, X. Recent Advances in Utilizing Transcription Factors to Improve Plant Abiotic Stress Tolerance by Transgenic Technology. Front. Plant Sci. 2016, 7, 67. [CrossRef]

20. Scharf, K.D.; Rose, S.; Zott, W.; Schoffl, F.; Nover, L. Three tomato genes code for heat stress transcription factors with a region of remarkable homology to the DNA-binding domain of the yeast HSF. EMBO J. 1990, 9, 4495-4501. [CrossRef] [PubMed]

21. Scharf, K.D.; Berberich, T.; Ebersberger, I.; Nover, L. The plant heat stress transcription factor (Hsf) family: Structure, function and evolution. Biochim. Biophys. Acta 2012, 1819, 104-119. [CrossRef] [PubMed]

22. Li, P.S.; Yu, T.F.; He, G.H.; Chen, M.; Zhou, Y.B.; Chai, S.C.; Xu, Z.S.; Ma, Y.Z. Genome-wide analysis of the Hsf family in soybean and functional identification of GmHsf-34 involvement in drought and heat stresses. BMC Genom. 2014, 15, 1009. [CrossRef] [PubMed]

23. Lin, Y.X.; Jiang, H.Y.; Chu, Z.X.; Tang, X.L.; Zhu, S.W.; Cheng, B.J. Genome-wide identification, classification and analysis of heat shock transcription factor family in maize. BMC Genom. 2011, 12, 76. [CrossRef]

24. Chauhan, H.; Khurana, N.; Agarwal, P.; Khurana, P. Heat shock factors in rice (Oryza sativa L.): Genome-wide expression analysis during reproductive development and abiotic stress. Mol. Genet. Genom. 2011, 286, 171-187. [CrossRef]

25. Xue, G.P.; Sadat, S.; Drenth, J.; McIntyre, C.L. The heat shock factor family from Triticum aestivum in response to heat and other major abiotic stresses and their role in regulation of heat shock protein genes. J. Exp. Bot. 2014, 65, 539-557. [CrossRef] [PubMed]

26. Nover, L.; Bharti, K.; Doring, P.; Mishra, S.K.; Ganguli, A.; Scharf, K.D. Arabidopsis and the heat stress transcription factor world: How many heat stress transcription factors do we need? Cell Stress Chaperon 2001, 6, 177-189. [CrossRef] 
27. Mishra, S.K.; Tripp, J.; Winkelhaus, S.; Tschiersch, B.; Theres, K.; Nover, L.; Scharf, K.D. In the complex family of heat stress transcription factors, HSfA1 has a unique role as master regulator of thermotolerance in tomato. Genes Dev. 2002, 16, 1555-1567. [CrossRef] [PubMed]

28. Yoshida, T.; Ohama, N.; Nakajima, J.; Kidokoro, S.; Mizoi, J.; Nakashima, K.; Maruyama, K.; Kim, J.M.; Seki, M.; Todaka, D.; et al. Arabidopsis HsfA1 transcription factors function as the main positive regulators in heat shock-responsive gene expression. Mol. Genet. Genom. 2011, 286, 321-332. [CrossRef]

29. Liu, H.C.; Liao, H.T.; Charng, Y.Y. The role of class A1 heat shock factors (HSFA1s) in response to heat and other stresses in Arabidopsis. Plant Cell Environ. 2011, 34, 738-751. [CrossRef]

30. Bechtold, U.; Albihlal, W.S.; Lawson, T.; Fryer, M.J.; Sparrow, P.A.C.; Richard, F.; Persad, R.; Bowden, L.; Hickman, R.; Martin, C.; et al. Arabidopsis HEAT SHOCK TRANSCRIPTION FACTORA1b overexpression enhances water productivity, resistance to drought, and infection. J. Exp. Bot. 2013, 64, 3467-3481. [CrossRef] [PubMed]

31. Schramm, F.; Ganguli, A.; Kiehlmann, E.; Englich, G.; Walch, D.; von Koskull-Doring, P. The heat stress transcription factor HsfA2 serves as a regulatory amplifier of a subset of genes in the heat stress response in Arabidopsis. Plant Mol. Biol. 2006, 60, 759-772. [CrossRef] [PubMed]

32. Charng, Y.Y.; Liu, H.C.; Liu, N.Y.; Chi, W.T.; Wang, C.N.; Chang, S.H.; Wang, T.T. A heat-inducible transcription factor, HsfA2, is required for extension of acquired thermotolerance in Arabidopsis. Plant Physiol. 2007, 143, 251-262. [CrossRef]

33. Xin, H.; Zhang, H.; Chen, L.; Li, X.; Lian, Q.; Yuan, X.; Hu, X.; Cao, L.; He, X.; Yi, M. Cloning and characterization of HsfA2 from Lily (Lilium longiflorum). Plant Cell Rep. 2010, 29, 875-885. [CrossRef] [PubMed]

34. Gong, B.H.; Yi, J.; Wu, J.; Sui, J.J.; Khan, M.A.; Wu, Z.; Zhong, X.H.; Seng, S.S.; He, J.N.; Yi, M.F. LlHSFA1, a novel heat stress transcription factor in lily (Lilium longiflorum), can interact with LlHSFA2 and enhance the thermotolerance of transgenic Arabidopsis thaliana. Plant Cell Rep. 2014, 33, 1519-1533. [CrossRef] [PubMed]

35. Gu, L.; Jiang, T.; Zhang, C.X.; Li, X.D.; Wang, C.M.; Zhang, Y.M.; Li, T.; Dirk, L.M.A.; Downie, A.B.; Zhao, T.Y. Maize HSFA2 and HSBP2 antagonistically modulate raffinose biosynthesis and heat tolerance in Arabidopsis. Plant J. 2019, 100, 128-142. [CrossRef] [PubMed]

36. Yokotani, N.; Ichikawa, T.; Kondou, Y.; Matsui, M.; Hirochika, H.; Iwabuchi, M.; Oda, K. Expression of rice heat stress transcription factor OsHsfA2e enhances tolerance to environmental stresses in transgenic Arabidopsis. Planta 2008, 227, 957-967. [CrossRef] [PubMed]

37. Li, Z.J.; Zhang, L.L.; Wang, A.X.; Xu, X.Y.; Li, J.F. Ectopic Overexpression of SlHsfA3, a Heat Stress Transcription Factor from Tomato, Confers Increased Thermotolerance and Salt Hypersensitivity in Germination in Transgenic Arabidopsis. PLoS ONE 2002, 16, 1555-1567. [CrossRef] [PubMed]

38. Song, C.; Chung, W.S.; Lim, C.O. Overexpression of Heat Shock Factor Gene HsfA3 Increases Galactinol Levels and Oxidative Stress Tolerance in Arabidopsis. Mol. Cells 2016, 39, 477-483. [CrossRef]

39. Poonia, A.K.; Mishra, S.K.; Sirohi, P.; Chaudhary, R.; Kanwar, M.; Germain, H.; Chauhan, H. Overexpression of wheat transcription factor (TaHsfA6b) provides thermotolerance in barley. Planta 2020, 252, 53. [CrossRef]

40. Xue, G.P.; Drenth, J.; McIntyre, C.L. TaHsfA6f is a transcriptional activator that regulates a suite of heat stress protection genes in wheat (Triticum aestivum L.) including previously unknown Hsf targets. J. Exp. Bot. 2015, 66, 1025-1039. [CrossRef]

41. Liu, A.L.; Zou, J.; Liu, C.F.; Zhou, X.Y.; Zhang, X.W.; Luo, G.Y.; Chen, X.B. Over-expression of OsHsfA7 enhanced salt and drought tolerance in transgenic rice. BMB Rep. 2013, 46, 31-36. [CrossRef] [PubMed]

42. Zang, D.D.; Wang, J.X.; Zhang, X.; Liu, Z.J.; Wang, Y.C. Arabidopsis heat shock transcription factor HSFA7b positively mediates salt stress tolerance by binding to an E-box-like motif to regulate gene expression. J. Exp. Bot. 2019, 70, 5355-5374. [CrossRef] [PubMed]

43. Fragkostefanakis, S.; Roth, S.; Schleiff, E.; Scharf, K.D. Prospects of engineering thermotolerance in crops through modulation of heat stress transcription factor and heat shock protein networks. Plant Cell Environ. 2015, 38, 1881-1895. [CrossRef]

44. Hahn, A.; Bublak, D.; Schleiff, E.; Scharf, K.D. Crosstalk between Hsp90 and Hsp70 Chaperones and Heat Stress Transcription Factors in Tomato. Plant Cell 2011, 23, 741-755. [CrossRef]

45. Ma, H.; Wang, C.T.; Yang, B.; Cheng, H.Y.; Wang, Z.; Mijiti, A.; Ren, C.; Qu, G.H.; Zhang, H.; Ma, L. CarHSFB2, a Class B Heat Shock Transcription Factor, Is Involved in Different Developmental Processes and Various Stress Responses in Chickpea (Cicer arietinum L.). Plant Mol. Biol. Rep. 2016, 34, 1-14. [CrossRef]

46. Xiang, J.H.; Ran, J.; Zou, J.; Zhou, X.Y.; Liu, A.L.; Zhang, X.W.; Peng, Y.; Tang, N.; Luo, G.Y.; Chen, X.B. Heat shock factor OsHsfB2b negatively regulates drought and salt tolerance in rice. Plant Cell Rep. 2013, 32, 1795-1806. [CrossRef] [PubMed]

47. Li, M.; Doll, J.; Weckermann, K.; Oecking, C.; Berendzen, K.W.; Schoffl, F. Detection of in vivo interactions between Arabidopsis class A-HSFs, using a novel BiFC fragment, and identification of novel class B-HSF interacting proteins. Eur. J. Cell Biol. 2010, 89, 126-132. [CrossRef]

48. Zhang, H.M.; Li, G.L.; Fu, C.; Duan, S.N.; Hu, D.; Guo, X.L. Genome-wide identification, transcriptome analysis and alternative splicing events of Hsf family genes in maize. Sci. Rep.-UK 2020, 10, 8073. [CrossRef]

49. Jiang, Y.L.; Zheng, Q.Q.; Chen, L.; Liang, Y.N.; Wu, J.D. Ectopic overexpression of maize heat shock transcription factor gene ZmHsf04 confers increased thermo and salt-stress tolerance in transgenic Arabidopsis. Acta Physiol. Plant. 2017, 40, 9. [CrossRef] 
50. Li, G.L.; Zhang, H.N.; Shao, H.B.; Wang, G.Y.; Zhang, Y.Y.; Zhang, Y.J.; Zhao, L.N.; Guo, X.L.; Sheteiwy, M.S. ZmHsf05, a new heat shock transcription factor from Zea mays L. improves thermotolerance in Arabidopsis thaliana and rescues thermotolerance defects of the athsfa2 mutant. Plant Sci. 2019, 283, 375-384. [CrossRef]

51. Li, H.C.; Zhang, H.N.; Li, G.L.; Liu, Z.H.; Zhang, Y.M.; Zhang, H.M.; Guo, X.L. Expression of maize heat shock transcription factor gene $\mathrm{ZmHsf06}$ enhances the thermotolerance and drought-stress tolerance of transgenic Arabidopsis. Funct. Plant Biol. 2015, 42, 1080-1091. [CrossRef]

52. Alexandre, C.; Moller-Steinbach, Y.; Schonrock, N.; Gruissem, W.; Hennig, L. Arabidopsis MSI1 Is Required for Negative Regulation of the Response to Drought Stress. Mol. Plant 2009, 2, 675-687. [CrossRef]

53. Aubert, Y.; Vile, D.; Pervent, M.; Aldon, D.; Ranty, B.; Simonneau, T.; Vavasseur, A.; Galaud, J.P. RD20, a Stress-Inducible Caleosin, Participates in Stomatal Control, Transpiration and Drought Tolerance in Arabidopsis thaliana. Plant Cell Physiol. 2010, 51, 1975-1987. [CrossRef] [PubMed]

54. Park, S.C.; Kim, Y.H.; Jeong, J.C.; Kim, C.Y.; Lee, H.S.; Bang, J.W.; Kwak, S.S. Sweetpotato late embryogenesis abundant 14 (IbLEA14) gene influences lignification and increases osmotic- and salt stress-tolerance of transgenic calli. Planta 2011, 233, 621-634. [CrossRef] [PubMed]

55. Bao, F.; Du, D.L.; An, Y.; Yang, W.R.; Wang, J.; Cheng, T.R.; Zhang, Q.X. Overexpression of Prunus mume Dehydrin Genes in Tobacco Enhances Tolerance to Cold and Drought. Front. Plant Sci. 2017, 8, 8. [CrossRef] [PubMed]

56. Liu, H.; Wang, Q.Q.; Yu, M.M.; Zhang, Y.Y.; Wu, Y.B.; Zhang, H.X. Transgenic salt-tolerant sugar beet (Beta vulgaris L.) constitutively expressing an Arabidopsis thaliana vacuolar $\mathrm{Na}+\mathrm{H}+$ antiporter gene, AtNHX3, accumulates more soluble sugar but less salt in storage roots. Plant Cell Environ. 2008, 31, 1325-1334. [CrossRef] [PubMed]

57. Iuchi, S.; Kobayashi, M.; Taji, T.; Naramoto, M.; Seki, M.; Kato, T.; Tabata, S.; Kakubari, Y.; Yamaguchi-Shinozaki, K.; Shinozaki, K. Regulation of drought tolerance by gene manipulation of 9-cis-epoxycarotenoid dioxygenase, a key enzyme in abscisic acid biosynthesis in Arabidopsis. Plant J. 2001, 27, 325-333. [CrossRef]

58. Park, H.Y.; Seok, H.Y.; Park, B.K.; Kim, S.H.; Goh, C.H.; Lee, B.; Lee, C.H.; Moon, Y.H. Overexpression of Arabidopsis ZEP enhances tolerance to osmotic stress. Biochem. Biophys. Res. Commun. 2008, 375, 80-85. [CrossRef] [PubMed]

59. Yoo, S.D.; Cho, Y.H.; Sheen, J. Arabidopsis mesophyll protoplasts: A versatile cell system for transient gene expression analysis. Nat. Protoc. 2007, 2, 1565-1572. [CrossRef] [PubMed]

60. Cao, J.M.; Yao, D.M.; Lin, F.; Jiang, M.Y. PEG-mediated transient gene expression and silencing system in maize mesophyll protoplasts: A valuable tool for signal transduction study in maize. Acta Physiol. Plant. 2014, 36, 1271-1281. [CrossRef] 